\section{FARIZA BENLYAZID: CINE FEMINISTA SOBRE LA IDENTIDAD PERSONAL}

\author{
Katjia Torres \\ Universidad Pablo de Olavide \\ mtorres@upo.es
}

\section{FARIZA BENLYAZID: FEMINIST CINEMA DEALING WITH PERSONAL IDENTITY}

\begin{abstract}
RESUMEN: El presente artículo analiza la visión íntima del conflicto de identidad de la mujer marroqui musulmana -entendido como la tensión entre la cultura colonial francesa y la árabe musulmanaofrecida por la cineasta tangerina Farida Benlyazid en su opera prima como directora y guionista, Bab samá maftúh / Une porte sur le ciel ("La puerta abierta del cielo", 1988). Benlyazid es una pionera del cine marroqui en el tratamiento del papel de la mujer musulmana en el seno del patriarcado marroqui por su particular concepción del feminismo y por su formación multicultural, que le permite emplear un lenguaje simbólico para universalizar su cine y transmitir el valor de ritos y rituales atávicos en el imaginario colectivo popular marroqui así como en el de su imaginario íntimo.
\end{abstract}

PALABRAS CLAVE: Europa/Norte de África, Farida Benlyazid, Islam, mujer, identidad.

\begin{abstract}
This article analyses Tangier's director Farida Benlyazid's personal vision of the identity conflict of the Muslim Moroccan woman (a conflict deriving from the tension between the French colonial culture and the Arab-Muslim one) as presented in her opera prima Bab samá maftúh / A Door to the Sky (1988), based on a script written by herself. Within the context of Moroccan cinema, Benlyazid is a pioneer in the treatment of the Muslim woman's role in the Moroccan patriarchal system due both to her peculiar understanding of feminism and to her multicultural upbringing, which allows her to deploy a symbolic language to universalize her films and transmit the value of rites and atavistic rituals of Morocco's popular collective imaginary and of her own intimate imaginary.
\end{abstract}

KEY WORDS: Europe/North Africa, Farida Benlyazid, Islam, women, identity.

Simplemente diré que trabajo sobre el tiempo, la memoria, el universo de las mujeres y el compromiso ciudadano, y que reservo un lugar para mi imaginario multicultural. Une porte sur le ciel (Una puerta al cielo), hecha en coproducción con Túnez y Francia, trataba de una búsqueda espiritual, del feminismo dentro del islam y de la noción del tiempo en las diferentes culturas.

BENLYAZID, 2007, 224.

\section{Farida Benlyazid (TÁnger, 10 de marzo de 1948): UNA CINEASTA MULTICULTURAL}

Una vez conocida la obra cinematográfica de esta original cineasta marroquí, no es difícil llegar a la conclusión de que ciertos aspectos de su mundo interior y de su biografía plasmados en su filmografía revelan su formación multicultural y la continua búsqueda de su identidad, muy marcada por el Islam y la cultura marroquí. A modo de apunte, en tres de los títulos señeros de su carrera, Bab samá maftúh (1988/9), A la recherche du mari de ma femme (1992) y Kaid nisá (1999), Benlyazid nos transmite, respectivamente, su desilusión por el feminismo europeo, su experiencia con la poligamia y su madurez emocional bajo la forma de una parábola sobre la superioridad de la mujer.
Bab samá maftúh plasma la crisis de identidad de una mujer marroquí musulmana creyente y practicante que vivió con entusiasmo la eclosión del feminismo en Francia y que, posteriormente, se desencantó de sus tesis. Benlyazid concibe el feminismo como un vehículo de entendimiento entre el hombre y la mujer, y en torno a este eje gira toda su obra y, en especial, Bab samá maftúh, su primer largometraje. La elección que hacemos de esta película frente a las dos restantes que la consagraron reside en que es el trabajo que mejor refleja esa catarsis personal, en el que afloran los estados emocionales de la infancia, adolescencia y madurez de la protagonista, alter ego de Benlyazid.

Farida Benlyazid nació en el seno de una familia de la alta burguesía de la Tánger internacional de los Protectorados, 
ciudad que, históricamente, ha sido cruce de caminos y un lugar de encuentros multiculturales. Igualmente, ha sido un enclave emblemático de la cinematografía marroquí de la segunda mitad del siglo XX (Schneider, 2008, 80), e inspiración de célebres títulos como Tangier (1946), Mission à Tanger (1949), Flight to Tangier (1953) y Casablanca (1942) (Schneider, 2008, 80), entre una cincuentena más.

Tras la independencia de Marruecos (1956), las políticas de incentivación de la cinematografía nacional fueron de muy escasa envergadura, provocando un cierto declive en los años 60 y 70 . No será hasta bien entrada la década de los 80 que esta industria inicie su recuperación, que se hará más notable en la segunda mitad de los años 90 (Sabah, 2010). Benlyazid participó en dicha recuperación junto con otros cineastas de renombre entre los que destaca especialmente Farida Bourquia, autora del primer largometraje producido en territorio nacional, Al-Jamra / La braise (1982) (Benlyazid, 2007, 223).

El interés de Farida Benlyazid por el cine le viene desde la infancia. Siendo muy niña, sufre la separación de sus padres. Su madre decide abandonar el seno familiar y dejar a Benlyazid junto a sus siete hermanos y hermanas bajo la tutela del padre, casado con su segunda esposa, y de su abuela paterna. En esta etapa de la separación, se refugia en el cine y en la lectura, vocaciones a las cuales su familia se opuso por considerar el mundo del cine un ámbito laboral poco apropiado para una joven de su condición social en aquellos tiempos:

Al cine ya no iba más que una vez a la semana, en compañia de mis hermanos. Mi padre nos decía entonces, sonriendo irónicamente: "Se burlan de vosotros, os cuentan historias y se quedan con vuestro dinero". Cuando veo esas producciones americanas que continúan atrayendo a las masas fascinadas, que pagan para ser manipuladas, me digo a mí misma que mi padre no estaba tan equivocado... Contrariamente a mis hermanos, no estaba resentida con mi madre por haberse ido. Comprendía su lucha de mujer por vivir su libertad.

Como ella, quería ser moderna; escuchaba los sermones de mi abuela, que me decía que, cuando fuera mayor, ya haría lo que quisiera.

No me rebelaba, mi padre siempre trataba de convencernos mediante la razón. Estaba muy presente, y era afectuoso y persuasivo. Comencé a mentir para no hacerle sufrir. En cuanto tenía dinero, hacía novillos para ir al cine que estaba al lado del instituto. También me refugiaba en los libros. Leía de todo: literatura rosa, literatura verde, novelas de éxito y hasta fotonovelas, que había descubierto en el colmo de la felicidad. Nadie controlaba mis lecturas y yo me aprovechaba de ello para evadirme sin moverme de casa. A los catorce años Simone de Beauvoir se convirtió en mi modelo [...]. Asi pues, dentro de mi cabeza vivía una vida paralela, adaptándome al modo de vivir de una chica obediente. (Benlyazid, 2007, 221)

Con 17 años, se casa con el cineasta Jillali Ferhati, un revolucionario condenado a muerte con quien tuvo dos hijas.

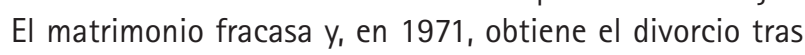
una dura batalla legal. Se marcha a París a cursar estudios de literatura y de cinematografía, donde se licencia, en 1976, en la Universidad de París VIII y en el Institut des Hautes Études Cinématographiques (IDHEC). Durante el siguiente año, consigue unas prácticas en París para trabajar en el cine, antes de regresar a Marruecos. Se casará en tres ocasiones, siendo en una de ellas la segunda esposa de un marido polígamo, y dará a luz a su tercer hijo. En la entrevista que concede a Juan Goytisolo recogida en el capítulo octavo de la serie televisiva Alquibla (1988), titulado Ver sin ser vista. La mujer en el Islam (con guión del propio Goytisolo), Farida Benlyazid explica cómo vivió la experiencia y los motivos que la llevaron a aceptar la poligamia de su marido. Sin hacer una defensa a ultranza de la poligamia, la considera una solución viable para la mujer que atraviesa dificultades personales concretas: ${ }^{1}$

Farida Benlyazid: Cuando se presentó el caso tuve que un señor que estaba casado. Me pidió que me casaría con él. Bueno me... De repente lo encontré muy raro, pero al pensarlo bien, me dije que era una buena solución.

Juan Goytisolo: ¿Crees que la poligamia es una solución aceptable para una mujer en estos tiempos?

Farida Benlyazid: Pues creo que sí. Sin ser... sin defender a la poligamia, tampoco, porque hasta en el Corán no se dice que hay que ser polígamo, pero a veces puede ser una solución. $Y$ hay gente que lo vive muy bien, años, bueno, toda la vida. En mi caso fracasó, después de una temporada, porque hubo una tercera mujer que ya no aceptaba la poligamia. Bueno claro, en ese caso preferí pedir el divorcio. Sigo sin estar en contra, porque fue un momento dado, una solución posible. (Goytisolo, 1988) 
Su posicionamiento se puede explicar en el estatus jurídico y social al que el Código del Estatus Personal de los años 70 y 80 sometía a la mujer marroquí musulmana, manteniéndola en una permanente minoría de edad legal y bajo la tutela patriarcal, que restringía las posibilidades de su posible emancipación económica y social. Para profundizar sobre esta cuestión el lector puede consultar Ghassan (1989) y Torres (2006).

En 1981, cuando consideró que Europa no tenía mucho más que aportarle en el ámbito personal y laboral, decidió regresar a Marruecos. Previamente, había producido Une brèche dans le mur (1978) y escrito el guión de Poupées de Roseau (1979), ambas de su exmarido Jillali Ferhati, además de haber dirigido su primer documental para la FR3, Identité de femme (1980), sobre las mujeres en la inmigración. A su regreso a Marruecos, toma conciencia de la situación de precariedad del cine marroquí, originada por la invasión del cine comercial proveniente de Hong Kong, Egipto, India y Estados Unidos (Hillauer, 2006, 327), y decide trabajar en colaboración con otros pocos cineastas, hombres y mujeres, pioneros contemporáneos suyos (Narjis Nejjar, Yasmine Fassari, Layla Marakchi, Zakia Tahiri o Fatema Zemmouri Ouazzani), la mayoría residentes en Europa, para "convencer a los poderes públicos de la importancia del cine para la cultura nacional":

Comencé siendo guionista. Ayudada por la nostalgia, tenía un deseo profundo de hablar de mi cultura. La vida en París me había agotado, y el progreso había perdido su atractivo [...]. Un día, a propósito de mi carrera cinematográfica, que estaba en sus comienzos, un periodista me dijo: "¿Qué has hecho para merecer esto?" Me tomé a risa su pregunta, como una ocurrencia, pero jamás la olvidé. Entre los que empezábamos, y que trabajábamos para impulsar el cine en Marruecos, había un deseo, una pasión, que nadie podía comprender.

Algunas películas filmadas después de la independencia habian arruinado a sus productores, y nadie creía que en Marruecos se pudiera hacer cine. Éramos cuatro gatos empeñados en administrar la miseria para propiciar la existencia de algunas imágenes de nuestra cultura. Pero habiamos llegado demasiado tarde: el mercado estaba tomado por los americanos, los egipcios y los indios, que habian instalado sus redes desde el principio. (Benlyazid, 2007, 222)
En 1986 se produce su despegue cinematográfico con el guión en castellano del largometraje Badis, de Mohamed Abderrahmán Tazi, una coproducción hispano-marroqui que saldrá a la luz cuatro años después y que será recibida por el público marroquí con cierto recelo, dada su predilección por las películas rodadas en francés o en árabe. Al año siguiente, produce Bab samá maftúh, el primer largometraje de los cinco que realizará, hasta el 2007, que la convertirán en la cineasta más prolija de su país ( $\mathrm{Ha}$ mdaoui, 2009) y sobre el que versará nuestro análisis más adelante. La repercusión de este largometraje la anima a crear la sociedad cinematográfica Tingitana Films (1991), con la que coproducirá Kaid nisá (1998), aclamada unánimemente por la crítica y el público marroquies, y se vuelca en la redacción del guión de este film y de $A$ la recherche du mari de ma femme (1992), de Abderrahman Tazi, que la consolidan nacional e internacionalmente como cineasta. En los diez años que distancian sus dos grandes éxitos como directora, Bab samá maftúh y Kaid nisá, se dedica a escribir guiones para otros directores de cine y teatro, y a colaborar en periódicos nacionales e internacionales, desarrollando su faceta de columnista para Le Libéral, con colaboraciones mensuales, El Mundo, Autrement, Oantara o El País (Benlyazid, 2003). Además, escribe los guiones del documental Aminata Traoré, une femme du Sahel (1993), en el que describe la lucha de esta gran intelectual, socióloga e investigadora, exministra de Cultura y de Turismo de Mali, contra la mundialización; del cortometraje Sur la terrasse (1995) (Benlyazid, 1996, 66-67), y de la pieza teatral Aide-toi, le ciel t'aidera (1997), destinada a concienciar sobre la lacra de la mortalidad materna, compaginando su faceta de guionista con la de narradora de relatos breves.

Inicia la década del 2000 escribiendo el guión de los telefilms Nia taghleb (2000) y El Boukma (2001) y dirigiendo el largometraje Casablanca, Casablanca (2002), sobre el secuestro de una niña en Casablanca, "que permitía hablar de los procesos incoados deprisa y corriendo en los veredictos decididos de antemano" (Benlyazid, 2007, 224). En la segunda mitad de la década dirige sus dos últimos largometrajes. El primero de ellos, La vida perra de Juanita Narboni / Juanita fi Tanya (2006) fue recibido por la crítica y el público de manera desigual. Está inspirado en la novela que el propio autor, Ángel Vázquez, le ofreció a Farida Benlyazid y que ella adaptó "como un testimonio de esa obra maratoniana que hacía revivir el Tánger de mi infancia" (Benlyazid, 2007, 224). El segundo de ellos es Casa Nayda, 
una película documental realizada por Farida Benlyazid y Abderrahim Mettou, y escrita por Dominique Caubet, sobre la efervescencia cultural y social de Marruecos a principios del siglo XXI, catalogada como "movida" (nayda), iniciada a finales de los 90. Igualmente, en ese mismo año, participa en el guión del film rodado en Marruecos Qosat warda / Histoire d'une rose, de Abdelmajid R'chich, último trabajo cinematográfico de la autora hasta la fecha.

Farida Benlyazid define su obra como un trabajo sobre el tiempo, la memoria, el universo de las mujeres y el compromiso ciudadano y su imaginario multicultural. Bab sama' maftuh / Une porte sur le ciel / A Door to the Sky (Una puerta al cielo, 1988), coproducida por Marruecos, Francia y Holan$\mathrm{da}$, es la película que aglutina todo su universo emocional y sus conflictos de identidad. Es un relato intimista sobre la búsqueda espiritual de la identidad de la mujer musulmana creyente -en su caso, cansada de la herencia de la cultura colonial y del progreso occidental-, a través de un Islam mistico que busca el amor universal como el único garante del bienestar humano. A pesar de haber sido considerado como un retrato estereotipado de la mujer tradicional musulmana frente al de la mujer musulmana moderna, dada la educación y el entorno tradicional de la propia directora, no es más que una simple descripción de la sociedad musulmana marroqui sujeta a sus códigos estrictos y al papel fundamental desempeñado por la mujer, tanto para la sociedad musulmana como para el propio Estado, dentro del marco de la espiritualidad. La película no es una respuesta al auge del fundamentalismo islámico marroquí (Hillauer, 2006, 338), sino que es fruto de la inspiración personal y pretende mostrar el aspecto cultual popular del Islam, desde el punto de las záuias (cofradías religiosas), tachadas por la propia ortodoxia estatal de heterodoxas, y no desde su vertiente fundamentalista o de religión de Estado.

Bab samá maftúh fue seleccionada y programada en diferentes festivales internacionales, como el Festival de San Sebastián de 2003, en el que participa dentro de la retrospectiva temática "Entre amigos y vecinos" y en el museo Guggemheim. La película circula en las universidades americanas, como la de UCLA (2008), y se incluye en el programa de marzo de 2005 del Instituto del Mundo Árabe de París. Es el largometraje que le abre las puertas a los circuitos internacionales y la consolida como una de los referentes del cine marroquí, norteafricano y europeo, gracias a las coproducciones realizadas con Suiza, España y Francia.
Farida Benlyazid, profeta en su tierra, recientemente recibió el homenaje de su ciudad a través de la asociación cultural Forum Culturel de Tanger por su trayectoria profesional y su aportación indiscutible al cine marroquí, así como por su proyección fuera de sus fronteras nacionales (Al-Fatouh, 2011).

\section{BAB SAMÁ MAFTÚH O LA BÚSQUEDA DE LA IDENTIDAD A TRAVÉS DEL AMOR}

Está concebida por la autora como un mosaico de imágenes simbólicas y oníricas entrelazadas que desvelan el inconsciente emocional de su protagonista, Nadia, una mujer educada en el patriarcado musulmán que ha madurado en la emancipación de la mujer y en la liberación sexual occidentales. Cansada de no identificarse con estos valores, siente que el reencuentro con sus orígenes pueden ayudarla a reconocerse a sí misma.

Nadia nace bajo el patriarcado musulmán tradicional de la alta sociedad de Fez, marcado por el sentimiento nacionalista a favor del sultán Mohamed $\mathrm{V}$, insignia del movimiento liderado por la alta aristocracia y los grandes terratenientes de los que formaba parte su padre, un marroquí culto, afrancesado y liberal, que tomó por esposa a una francesa de buena familia que le dará tres hijos a los que educa en las tradiciones y en la fe del Islam. De este matrimonio nacen tres hijos, de los cuales Nadia es la menor. A diferencia de su hermana Laila, que reside en Fez y está casada con un marroquí, Driss y Nadia están afincados en Francia y han echado raíces con parejas desvinculadas de la cultura marroqui y de las tradiciones del Islam.

Los tres hijos se reúnen en Fez para asistir al entierro de su padre, pero una vez finalizado éste, Driss decide regresar con su familia a Francia, mientras que Nadia opta por quedarse, abrumada por una profunda crisis de identidad ocasionada por los dulces recuerdos de su niñez que invaden su memoria, lo que la sume en un encierro voluntario. Se siente culpable por haber abandonado su país, sus tradiciones y su propia lengua materna (el árabe), para adoptar la cultura del antiguo colono (el francés), así como por haber vivido en el país que colonizó su pueblo. Su hermana, preocupada por su estado depresivo, la anima a que se reúna con las mujeres congregadas en torno a una 
recitadora de Corán, Lalla Kirana (Doña Kirana), para orar por el alma de su padre $y$, tras sumergirse en la recitación de los versículos coránicos, inicia un viaje en busca de su propia identidad.

Merodear por la soledad de los rincones de la casa-palacio le ayuda a meditar y a retrotraerse a su infancia. En una de sus estancias preferidas de la casa, la que alberga los retratos familiares y óleos de desnudos femeninos, contempla los retratos de su madre y del lector de Corán (muqri), un negro de origen bereber al servicio doméstico familiar, Ba Sassi, que le evocan su infancia feliz. Esta sala refleja la mentalidad liberal moderada predominante en la casa, conciliadora con la tradición árabe musulmana y la modernidad laica occidental. La representación figurativa del cuerpo humano -especialmente el desnudo- de la que se sirve Farida Benlyazid como recurso de evocación por su fuerte contenido simbólico, no es aceptable en el Islam tradicional conservador y purista, puesto que es considerado como una transgresión de los principios fundamentales.

Ba Sassi, imagen simbólica de las relaciones paternofiliales entre el varón adulto y la niña en el imaginario colectivo musulmán, desempeña el papel transcendental de dirigir sus pasos hacia su decisión final, ${ }_{1}^{2}$ en su labor de educador y cómplice, hasta que la niña alcanza los 6 ó 7 años, momento en el que la moral tradicional imposibilita el acercamiento entre el hombre adulto y la niña. Sutilmente, Farida Benlyazid deja entrever la relevancia de Ba Sassi en el seno familiar, propiciada por la estrecha relación que mantenía con su madre.

De manera progresiva, Nadia se desvincula de su etapa europea, rompe con su pareja, Jean Phillipe, y profundiza en sus raíces de la mano de su guía espiritual, la recitadora del Corán Lalla Kirana, quien se encargará de inculcarle los fundamentos del Islam a través de las enseñanzas del Corán, por considerarlo única respuesta a sus dudas existenciales. Inicialmente, a los ojos de Nadia, Lalla Kirana es una fuente válida de transmisión del conocimiento, a pesar de su discurso crítico poco reflexivo, a tenor de las respuestas que Nadia recibe a sus dudas:

Eso es del hombre que no sabe dominarse y se cree con derecho a sobrepasar los límites impuestos por Dios. Es del que abandona la verdadera religión, para su provecho, con un único fin material. Él forma parte de los hipócritas, de los que hablan de Dios en el santo Corán. Tú no vas a ser quien cambie el mundo, nadie puede hacerlo. Así lo ha querido Dios y lo que se nos pide es que hagamos nuestra propia crítica, que seamos conscientes de nuestros actos antes de juzgar a los otros. Los demás, déjaselos a Dios. Él tiene entre sus manos el destino de sus criaturas. El hombre, sea el que sea, no podrá cambiar este mundo. Es una locura. El hombre se equivoca en sus cálculos, se pone en el lugar de Dios, transcendiéndole en insostenible comparación, se pone en el lugar del ángel, de la hiena, del lobo. Olvida que es el hijo de Adán. Es verdad que en el hombre se encuentran estas cualidades, porque representa a la Creación. Él tiene que buscar el equilibrio.

A medida que Nadia va progresando en su interiorización espiritual, experimenta brotes ascéticos. Ante esta situación, Lalla Kirana le recomienda, para procurarse su sosiego espiritual, que se inicie en la disciplina de la oración, vía de aproximación del creyente al sí-mismo y al conocimiento directo de Dios, y que lea a pensadores iluminados y místicos musulmanes acordes al estadio iniciático en el que se encuentra. Desde un principio, Nadia no disimula su nula simpatía por el Islam institucional de su mentora y opta por cerrar parte de la casa familiar y llevar una vida de ascesis. A raíz de esta inflexión en lo personal, comienza a tener sueños reveladores en los que se le aparece Ba Sassi -con aspecto de anciano o de joven, pero siempre vestido de blanco y con un tocado cubriendo su cabeza-. Los sueños que tiene Nadia a lo largo de la película aportan información sobre su imaginario personal y su estado emocional, muy valioso para comprender los problemas de identidad de las mujeres educadas y que viven a caballo entre dos mundos en conflicto, el del colono y el colonizado.

Los buenos augurios de los que es portador Ba Sassi la animan a convertir su casa familiar en una záuia, una especie de centro de acogida para mujeres necesitadas de ayuda psicológica, o, incluso, para ofrecerles un refugio lejos de su entorno familiar. En esta nueva fase de su vida, Nadia se ha habituado a la disciplina de la oración. La labor educadora desempeñada por la záuia es pronto conocida en la ciudad de Fez y en otras zonas del país, atrayendo la llegada de mujeres de muy diverso origen y condición, transformándose en un lugar de bienestar, plenitud y de sensación de libertad donde construir una paz a la medida de las propias necesidades. En este ambiente propicio, 
Nadia comienza a sentir deseos de conocer, de reflexionar sobre sí misma y deja hablar a la voz de su conciencia libre, sin velos. Bajo este estado de sosiego espiritual se intensifican las visitas del espíritu de Ba Sassi, quien le anuncia la buena nueva de ser tocada por la mano divina:

\section{Te estaba esperando. ¡No temas! ¡Escúchame bien! (Ríe).} No he venido por la záuia. ¡No temas! No he venido por ti. Soy creyente. Esta casa es sagrada. Debéis sacrificar una vaca y hacer una noche de aïssaoua [trance extático salmodiando el nombre de Dios].

Esta casa necesita perfumes y trances.

A partir de este momento, los trances ascéticos y visiones milagrosas se intensifican, dándole fama de curandera en toda la ciudad. A pesar del aparente equilibrio emocional de Nadia, siente una profunda insatisfacción personal, a la que consigue poner fin tras la visita a la záuia de Bahia, una musulmana nacida en el extranjero que le hace cuestionarse los motivos que la llevan a encerrarse. En el transcurso de la conversación que mantienen, Bahia escoge de la biblioteca del dormitorio de Nadia la obra Une saison en enfer ("Una temporada en el infierno") de Arthur Rimbaud y le recita los versos finales de Mauvais sang ("La mala sangre"):

En cuanto a la felicidad establecida, doméstica o no... no, no puedo. Estoy demasiado disperso, demasiado débil. La vida florece por el trabajo, vieja verdad: en cuanto a mí, mi vida no es suficientemente pesada, vuela y flota lejos por encima de la acción, ese caro lugar del mundo. ¡Cómo me vuelvo solterona, lo que me falta, el coraje de amar la muerte! Si Dios me concediera la calma celeste, aérea, la plegaria, como a los antiguos santos. ¡Los santos! ¡Qué fuertes! Los anacoretas jartistas como ya no los hay! ¡Farsa continua! Mi conciencia me da ganas de llorar. La vida es la farsa en la que todos figuramos. (Rimbaud, 1873, 17-18)

Esas palabras, versos en el original, la empujarán a abandonar definitivamente la záuia para ir a Mouley Abdessalam, al sur de Tánger, donde se encuentra el mausoleo del célebre santón sufí del siglo XII, Abdeslam Ben Mchich Alami. $^{3}$

En los tres días de ayuno previos a su viaje a Mouley Abdessalam, su hermana Laila le pide que haga uso de sus dotes curativas y atienda al hijo de una amiga suya,
Abdelkrim, alcohólico y con trastornos de conducta. Nadia accede a conocer al joven, un "bon vivant" que no se adapta a la vida monótona y espiritual de Fez y que se siente presionado por las exigencias del entorno tradicional de la ciudad. De sus encuentros y conversaciones surge un entendimiento emocional, basado en el inconformismo, la búsqueda del equilibrio espiritual y el amor armónico y deciden, finalmente, viajar juntos a Mouley Abdessalam para iniciar su búsqueda particular del amor.

Farida Benlyazid, con esta película, hace su personal crítica al feminismo de este momento al que considera poco conciliador con el género masculino. En la entrevista concedida a Juan Goytisolo, emitida en el capítulo mencionado de la serie televisiva Alquibla (1988), confiesa la desilusión que le supuso el comprobar el desconocimiento por parte del feminismo francés de los problemas de las mujeres magrebies musulmanas al tiempo que su desinterés:

Al salir de Marruecos, era en el 71, [me] acababa de divorciar, mi primer matrimonio había fracasado y al llegar me encontré con el movimiento feminista en Paris que estaba muy fuerte [...] y pensé que podiamos hacer algo juntas. Pero rápidamente he visto que no teníamos los mismos problemas y que no querían ver la realidad de una mujer árabe. Tenían unos estereotipos y lo que más me interesaba a mí no lo podía lograr, pero al revés, me planteaban como futuro mi pasado que es de vivir entre mujeres, eso yo lo sé muy bien lo que es y me gusta ¿no?, pero me interesaba también conocer el mundo de los hombres, al exterior. (Goytisolo, 1988)

\section{EL LENGUAJE SIMBÓLICO DEL IMAGINARIO MULTICULTURAL de Farida Benlyazid en Bab samá maftúH}

Como su ciudad natal, Farida Benlyazid es una sintesis de las influencias bereberes, árabes y occidentales. Gracias a su multiculturalidad y a su condición de políglota, es consciente de que la lengua es reflejo del pensamiento de un pueblo. Los títulos de la directora que mayor difusión internacional han alcanzado han sido aquellos en los que ha privilegiado la imagen silenciosa frente al idioma, caso de Badis, rodada en castellano, de Bab samá maftúh, rodada en francés, árabe y en dáriya (dialecto de la zona centro del país) o de Kaid nisá / Ruses de femmes, rodada en árabe y dáriya, su mayor éxito comercial a nivel nacional. 
La equilibrada combinación de la imagen y de la palabra concisa es la marca de identidad de toda su obra cinematográfica. En Bab samá maftúh consigue, a través de imágenes simbólicas, representar el valor de los recuerdos infantiles de su protagonista, la crisis de identidad que atraviesa en la edad adulta y su posterior proceso de madurez personal. Los escasos diálogos, en francés, en árabe y en dáriya, funcionan como glosas que descifran el carácter simbólico de las imágenes, logrando transmitir al gran público el significado y la transcendencia de ciertos ritos atávicos que dominan a la mujer musulmana, el funcionamiento del patriarcado musulmán marroquí tradicional y los miedos que le generan, recurriendo a alegorías, mitos y figuras de su particular imaginario multicultural. A continuación, señalamos algunos de los más relevantes para comprender el sentido de esta obra.

\section{LOS SÍMBOLOS: LA PUERTA ABIERTA DEL CIELO}

Bab samá maftúh o "la puerta abierta del cielo" es toda una evocación al deseo infantil de ver cumplidos todos nuestros sueños. ${ }^{4}$ Farida Benlyazid concede a Nadia su particular "Noche del destino" en el momento crítico cuando la záuia que regenta necesita remontarse económicamente, incapaz de sostenerse exclusivamente de las aportaciones caritativas que recibe. Así, tras la ruptura del ayuno preceptivo a la caída del sol, después de salir las mujeres de la casa a la mezquita, Nadia decide quedarse y llevar a cabo lo que una voz en sus sueños le invitó a realizar días antes: cavar bajo una palmera de su jardín. Este sueño se produce tras la celebración de un trance (aïssaoua) en el que se le aparece el espectro de Ba Sassi vestido de blanco, salmodiando y participando del mismo. Esta visión le abre su mente y su espíritu "a una dimensión que no sabía que existía" (Hillauer, 2006, 340). En mitad de la noche, mientras pasea en torno al árbol, del cielo surge un rayo luminoso, cual espada de luz, indicándole el lugar exacto donde cavar. Tras hacerlo, descubre un pequeño cofre lleno de joyas que enseñará al resto de mujeres de la casa y que utilizará para salvar la záuia.

Esta escena es una alegoría de la existencia divina por medio de símbolos universales como el árbol esbelto y perpendicular, la palmera, el rayo de luz descendente del cielo nocturno y el tesoro enterrado o kawzar. ${ }^{5}$ El árbol, identificado con el destino humano, es introductor de cierto mesianismo, se encuentra ubicado en la casa, el símbolo de la intimidad y de la feminización.

\section{LA CASA-PALACIO-ZÁUIA}

Farida Benlyazid hace de la casa natal de Nadia la "morada" de su intimidad, su asiento, en principio, definitivo, la protección del "universo en contra", es decir, del mundo exterior al muro de su morada, que Farida Benlyazid identifica con el universo masculino. Nadia hace de esta casa un "edificio habitable" no solo por ella y el fantasma de Ba Sassi, sino también por las mujeres que necesitan ese reposo espiritual que le ofrece la záuia. Intramuros, Nadia desarrolla su espiritualidad, lo que la hace granjearse la fama de sanadora y recibir el apodo de "Lalla Charífa" (la noble de espíritu), en reconocimiento de su elevado grado espiritual.

No obstante, su espiritualidad no escapa de su espíritu crítico y racional. No acepta la religión institucional del Estado, a la que define como "el opio del pueblo", ni acepta seguir los preceptos religiosos que atenten contra su condición de mujer, esto es, el inmovilismo social preconizado, el determinismo del ser humano y la fe ciega. Nadia se interesa más por el sufismo que le da respuestas a su anhelo, la búsqueda del amor universal, entendido como el sentimiento nacido de la unión espiritual de dos almas, en este caso, de un hombre y una mujer que se compenetran hasta hacerse uno. En el instante en que Nadia toma consciencia de que este es su objetivo, decide abandonar la záuia, puesto que no quiere limitarse al conocimiento del mundo femenino y no debe romper el estatus de recinto vetado a la presencia masculina de la záuia. El conocimiento del mundo femenino es algo que para ella está superado. Por ello, toma la decisión de marcharse al sur de Tánger, a Mouley Abdessalam, donde pueda emprender su viaje al amor armónico. Entre tanto, conoce a su futuro compañero en su viaje espiritual al amor.

\section{EL AMOR ENTRE HOMBRE Y MUJER Y UN SIMBOLISMO}

La iconografía puesta en escena por Farida Benlyazid para la representación del amor armónico entre hombre y mujer, 
inspirado por el sufismo, es el abrazo silencioso y la mirada reciproca penetrante de dos iguales vestidos de blanco. Así se conocen Nadia y Abdelkrim, y así será la escena final que concluya Bab samá maftúh, un primer plano ascendente desde su imagen dirigiéndose a un cielo azul limpio de nubes. El amor entre hombre y mujer, unión de dos voluntades, es el origen del amor divino. Esta unión puede establecerse en tres grados o "moradas". La primera de ellas es la del "bayt al-muharem" o "la morada de lo oculto", del harén, donde no se permite la entrada a extraños. Como vimos, Nadia se siente insatisfecha en este estadio y resuelve ir un paso más allá cuando decide abandonar la záuia y prepararse para peregrinar a Mouley Abdessalam. Inesperadamente, se cruza en su camino Abdelkrim, con quien siente que juntos evolucionan de manera unánime en sus voluntades, sin que se produzca la dominación del uno sobre el otro. Han logrado llegar al segundo estadio de su unión emocional, pasan del "bayt al-muharem" al "bayt al-muqaddas" o "la morada de lo sagrado", donde han abandonado su anterior yo. Se encuentran en un estadio inferior al "amor imparcial", el máximo que se puede alcanzar.

Con esta hermosa imagen, Farida Benlyazid critica el inmovilismo del Islam institucional que persigue la involución de ser humano, contraria a su condición natural $y_{\text {, en }}$ particular, el estancamiento social y emocional de la mujer musulmana. Entiende que al ser humano le es connatural la evolución, la transformación y la sociabilidad, y que debe desarrollar sus aptitudes en sociedad y no de manera aislada e incomunicada.

\section{ConcLusión}

Bab samá maftúh es una alegoría sobre el amor divino y la vía para lograrlo, que para Farida Benlyazid no es otra que el amor armónico entre el hombre y la mujer. A pesar de no constituir ningún tipo de transgresión para los fundamentos del Islam, los sectores religiosos tradicionales del pais recibieron esta obra con fuertes críticas, centradas, sobre todo, en los aspectos paganos.

A través de la figura espectral de Ba Sassi, la película condena los efectos negativos que comportan el aislamiento social de la mujer y la separación de los sexos en las sociedades musulmanas. Ba Sassi, el espíritu "verdadero", es la representación arquetípica del complejo paternal de Nadia, el origen del que parten sus convicciones, las prohibiciones y los consejos decisivos en su vida (Jung, 1948, 21 y 22). El gran logro de Farida Benlyazid en esta su primera obra como directora y guionista es haber conseguido traducir con el lenguaje de las imágenes ciertos elementos árabes musulmanes difícilmente transferibles a culturas occidentales y que sean fácilmente comprensibles para el gran público.

\section{NOTAS}

1 La cita es una transcripción literal de la respuesta de Farida Benlyazid a Juan Goytisolo en la que respetamos las incorrecciones gramaticales para conservar la espontaneidad de su respuesta.

2 La literatura marroquí contemporánea escrita por mujeres ha dedicado gran número de páginas a las relaciones edípicas paterno-filiales en el seno del patriarcado árabe musulmán, siendo uno de los títulos más relevantes la novela El velo al desnudo (2007) de la tangerina Badia Hadj Nasser.
3 Un "polo" del Islam (qotb) -el grado más elevado en la santidad y la espiritualidad-, considerado el mejor guía espiritual para la búsqueda del conocimiento de uno mismo.

4 Hace referencia, a la "Noche del destino", la noche de luna nueva del 26 al 27 del mes de ramadán, en la que se abren las puertas del cielo en el momento en el que le es revelado el Corán al profeta Mahoma. Esa noche los musulmanes alzan sus miradas para ver las puertas abiertas con el deseo de ver cumplidos todos sus deseos: "Todos los niños musulmanes han mirado el cielo fijamente esa noche" (Hillauer, 2006, 340).
Fecha de recepción: 30 de abril Fecha de admisión: 30 de mayo 
5 Kawzar es un término coránico que hace referencia a las bendiciones abundantes, personificadas en Fátima -hija del Profeta-, la primera persona en entrar en el Paraíso por su pureza, castidad, su renuncia y altruismo (Cortés, 1999, 824).

\section{BIBLIOGRAFÍA}

Al-Fatouh, Ahmed: "Homage à Farida Belyazid". Disponible en http://forumcultureltanger.org/index.php?view $=a$ rticle $=$ catid $=40 \% 3$ A cine $m a \& i d=51$. Consulta 14/03/2011.

Benlyazid, Farida (1996): "La terrasse: le lieu du posible", Qantara: magazine des cultures árabe et méditerranéenne 18, 66-67.

Benlyazid, Farida: "¿Por qué el pañuelo?" El Pais.es. Disponible en http://www.elpais.es/articulo.html?xref $=2003091 \ldots$ pe $=$ Tes\& anchor=elpepiopi\&print $=1 \&$ d_date $=20030914$. Consulta: 12/12/2010.

Benlyazid, Farida (2007): "El cine dirigido por mujeres", Quaderns de la Mediterrània 7, 222-224.

Cortés, Julio (1999): El Corán, Barcelona, Herder.

Durand, Gilbert (1982): Las estructuras antropológicas de lo imaginario, Madrid, Taurus.

Fernández Suzor, Cecilia (2005): "La directora de cine, Farida Benlyazid, que acaba de dirigir una coproducción hispanomarroquí, espera que surjan distribuidores españoles interesados por el cine marroquí", Afkar-ldeas 6, 108-109.

Ghassan, Ascha (1989): Du statut inférieur de la femme en Islam, Paris, L'Harmattan.

Goytisolo, Juan (1988): Ver sin ser vista. La mujer en el Islam, Alquibla, cap. 8, Madrid, TVE (27,55 min.).
Hadj Nasser, Badia (2007). El velo al desnudo, Alcalá la Real, Alcalá.

Hamdaoui, Djamil: "Sinima al-mar'ati fiI-Magrib". Disponible en http://www. almothaqaf.com/index.php?option= com_content\&view $=$ article\& $i d=7926$ : 2009-11-25-13-11-25. Consulta: 31/ 01/2011.

Hillauer, Rebecca (2006): Encyclopaedia of Arab Women Filmmakers, Cairo, American University in Cairo Press.

Jung, Carl G. (1948): Simbología del espíritu, Madrid, Fondo de Cultura Económica, 1998.

Rimbaud, Arthur (1873): Una temporada en el infierno, Santa Fe, El Cid Editor, 2004.

Sabah, Abdelkhalek (2010): "Aux hommes revenaient jadis la création et la maîtrise de la technique, tandis que les femmes étaient cantonnées à être de petits mains: $Y$ a-t-il une femme derrière la caméra?" Disponible en: $h t t p: / / w w w . l i b e . m a$. Consulta: 14/03/2011.

Shafik, Viola (1998): Arab Cinema: History and Cultural Identity, Cairo, American University in Cairo Press.

Schneider, Simona (2008): "Tanger fait son cinema", La pensée de midi. Tanger vielle frontière 23, 80-89. Disponible en http://www.lapenseedemidi.org/. Consulta: 3/1/2011.

Torres, Katjia (2006): "Estatus jurídicosocial de la mujer en Marruecos", en Desde Andalucía: Mujeres del Mediterráneo, ed. Mercedes Arriaga Flórez, Sevilla, ArCiBel, 465-497.

\section{FILMOGRAFÍA DE FARIDA BENLYAZID}

Producción: 1978, Une brèche dans le mur, de Jilali Ferhati (35 mm / $80 \mathrm{~min}$ ).

Realización: 1979, Identité de femme.
Dirección y guión: 1988, Bab samá maftúh / Une porte sur le ciel / A Door to the Sky (35 mm / $100 \mathrm{~min}$ ). 1995, Sur la Terrasse / On the Balcony (26 min). 1999, Kaid nisá / Ruses de femmes / Women's Wiles (35 mm / $90 \mathrm{~min}$ ). 2002, Casablanca, Casablanca / Dar al-Baydá, Dar al-Baydá (35 mm / 90 min). 2005/6, Juanita fi Tanya / The Wretched Life of Juanita Narboni / La vie de chien de Juanita Narboni / La vida perra de Juanita Narboni (35mm ( $101 \mathrm{~min}$ ).

Guión: 1979, Poupées de roseau, de Jillali Ferhati (35 mm / $88 \mathrm{~min})$. 1988, Badis (35 mm / $90 \mathrm{~min}$ ). 1993, À la recherche du mari de ma femme / Al Bath an zaouj imaraâti $(35$ mm / 88 min). 2000, Qosat warda / Histoire d'une rose / Story of a Rose, de Abdelmajid R'chich (35 mm / $85 \mathrm{~min}$ ). 2007, Deux femmes sur la route / Tarik al-Ayalat de Farida Bourquia (35 $\mathrm{mm}$ ( $90 \mathrm{~min}$ ).

Documental: 1993, Aminata Traoré / Femmes du Sahel / Aminata Traoré, a Woman of the Sahel (26 min). 1994, Contra bande. 2007, Casa Nayda (52 min), en colaboración con Dominique Caubet.

Telefilmes: 2000, Nia taghleb, para la 2M marroquí (86 min). 2001, El Boukma, para la $2 \mathrm{M}$ marroquí (90 min).

\section{FILMOGRAFÍA}

Casablanca (Dir. Michael Curtiz, 1942).

Tangier / Tánger (Dir. George Waggner, 1946).

Mission à Tanger (Dir. André Hunebelle, 1949).

Flight to Tangier/Vuelo a Tánger (Dir. Charles Marquis Warren, 1953).

Al-Jamra / La braise (Dir. Farida Bourquia, 1982). 